\title{
Effects of distance between objects and distance from the vertical axis on shape identity judgments
}

\author{
ALINDA FRIEDMAN and DANIEL J. PILON \\ University of Alberta, Edmonton, Alberta, Canada
}

\begin{abstract}
In three experiments, we independently manipulated the angular disparity between objects to be compared and the angular distance between the central axis of the objects and the vertical axis in a mental rotation paradigm. There was a linear increase in reaction times that was attributable to both factors. This result held whether the objects were rotated (with respect to each other and to the upright) within the frontal-parallel plane (Experiment 1) or in depth (Experiment 2), although the effects of both factors were greater for objects rotated in depth than for objects rotated within the frontal-parallel plane (Experiment 3). In addition, the factors interacted when the subjects had to search for matching ends of the figures (Experiments 1 and 2), but they were additive when the ends that matched were evident (Experiment 3). These data may be interpreted to mean that subjects normalize or reference an object with respect to the vertical upright as well as compute the rotational transformations used to determine shape identity.
\end{abstract}

There are compelling reasons to believe that people recognize objects by using a frame of reference that is either viewer centered (and, therefore, viewpoint specific) or environmentally based (e.g., McMullen \& Farah, 1991; McMullen \& Jolicoeur, 1990; Palmer, Rosch, \& Chase, 1981; Rock, 1974; Rock \& DiVita, 1987; Tarr \& Pinker, 1989, 1990, 1991). In the present experiments, we tried to pinpoint the influence of the environmental reference frame. We focus on how shape identity judgments to pairs of unfamiliar three-dimensional (3-D) objects are influenced by the distance between the objects with respect to each other as well as by the distance between the orientation of their longest axes and the environmental upright. Because both factors influence performance, we conclude that subjects encode the position of objects in space with respect to the upright in order to make judgments about their shape.

There is already empirical support for the idea that familiar objects are represented with respect to a point of view that coincides with the environmental upright. For example, McMullen and Jolicoeur (1990) had subjects name line drawings of familiar objects, and they found that naming time increased as a function of the distance between the tops of the objects and their normal upright

Portions of these experiments were presented at the 1991 meeting of the Psychonomic Society. The research was supported by the Natural Sciences and Engineering Research Council of Canada. We thank Joy Williams for collecting the data, Christina Gagne for analyzing portions of it, and Don Heth and Doug Wahlsten for helpful discussions about the analysis. We would also like to acknowledge the contributions made by David Hall. In addition, the manuscript was improved considerably by Norman Brown, Pierre Jolicoeur, an anonymous reviewer, and, especially, Geoff Loftus. Requests for reprints should be addressed to A. Friedman, Department of Psychology, University of Alberta, Edmonton, AB, Canada T6G 2E9 (e-mail: alinda@ psych.ualberta.ca). position (see also Jolicoeur, 1985). Similarly, Palmer, Rosch, and Chase (1981) showed that subjects named photographs of objects more quickly when the objects were displayed in orientations that a different group of individuals had judged as "canonical"; typically, that meant an upright, three-quarters frontal view. These findings are important because naming objects does not require a left/right or mirror-image discrimination (as do the judgments required in many mental rotation studies; see Corballis, 1988, for review). Consequently, the influence that the location of the top of a familiar object has on the time it takes to name it must be due to the discrepancy between the presented orientation of the stimulus and the orientation in the memory representation to which the stimulus is being compared.

McMullen and Jolicoeur (1990) also had subjects perform various tasks while their heads were tilted; tilting a subject's head allows one to separate the influence of the environmental from the retinal (or viewer-centered) frame. Under these circumstances, subjects named objects by using a reference frame closer to the retinal upright, whereas they discriminated right- from left-facing objects by using a reference frame closer to the environmental upright. Similarly, Corballis, Nagourney, Shetzer, and Stefanatos (1978), who also used a head-tilt manipulation, found evidence that subjects used an environmental reference frame when they made normal/mirrorimage discriminations of familiar alphanumeric characters.

The difficulty with using familiar objects or characters to investigate the frame-of-reference issue, however, is that the objects are familiar; in particular, the advantage for the upright view (whether or not it coincides with the retinal upright) cannot be attributed solely to perceptual processes. Instead, the advantage of upright objects could be due to the fact that these objects are seen in their upright positions more frequently than in other 
orientations, so their memory representations reflect this fact. Indeed, Tarr and Pinker (1989) and Humphrey and Kahn (1992) had subjects learn novel 2-D and 3-D objects, respectively, presented in specific orientations, and found that the subjects compared previously unseen stimuli with the view-specific representations they had acquired during the learning phase. However, this begs the question of what subjects do when comparing objects for which they do not necessarily have view-specific representations, because, for example, the objects are truly unfamiliar. This question is important because when subjects compare unfamiliar objects, we can determine whether use of an environmental reference frame is characteristic of fundamentally perceptual processes, or reflects characteristics of the memory representation with which a stimulus is being compared.

To address whether subjects use an environmental reference frame to compare unfamiliar objects, Friedman and Hall (1993) had subjects whose heads were either upright or tilted judge the shape identity of pairs of unfamiliar 3-D objects in a standard mental rotation paradigm (Shepard \& Metzler, 1971). The objects were seen equally often in all tested orientations, so that a given orientation (e.g., the vertical) would not be biased. The objects had been "spun" in depth around an axis that was parallel to their own axes of elongation, and they were aligned top to bottom with each other, so it was unnecessary for the subjects to search for corresponding ends or parts before beginning the rotation process (see Just \& Carpenter, 1976). Further, because the objects had been rotated in depth, the subjects had to encode their 3-D structure to perform the task successfully. The pairs of objects were oriented vertically, horizontally, or were tilted $45^{\circ}$ within the frontal-parallel ("picture") plane, and, because they were unfamiliar, their orientation with respect to the vertical axis was measured as a function of the orientation of their principal axes of elongation.

When the subjects were upright themselves, encoding was faster and more accurate for the vertically oriented objects than it was for the objects tilted $45^{\circ}$; that is, the intercept of the reaction time (RT) function was $470 \mathrm{msec}$ higher in the tilted-object condition than in the verticalobject condition. In addition, encoding was faster and more accurate for the tilted objects than it was for the objects that were oriented horizontally (the difference between intercepts was $366 \mathrm{msec}$; Friedman \& Hall, 1993).

Because it took the subjects longer to encode the objects as a function of the angular distance between their main axes of elongation and the vertical axis, and because this distance was irrelevant to the identity judgments, we conjectured that the vertically oriented objects must have been consistent with a frame of reference that the subjects used preferentially when performing this task, whereas the relation between the stimuli and the vertical axis had to be computed for tilted and horizontal objects. In particular, we conjectured that, in making judgments about unfamiliar shapes, subjects determine how objects are aligned with respect to the upright; to do so, they use the principle axis of elongation, if there is one. In addition, subjects bring the objects into congruence with each other during the mental rotation component of the task. If this view is correct, then objects that are already upright would have an advantage over those that are not. The data from the condition in which the subjects' heads were tilted corroborated this idea, but it also provided evidence for use of a subjective, viewercentered frame of reference under some circumstances. In particular, when the subjects' heads were tilted, the time it took them to encode both vertically and horizontally oriented objects remained the same as that when their heads were upright, which implicates the environmental reference frame. However, it became possible for the subjects to encode the tilted objects as quickly as they encoded the vertically oriented objects, which implicates the subjective reference frame. Thus, because the responses to the vertically oriented objects did not change, whereas those to the tilted objects became faster, there was evidence that the subjects used both an environmental and a subjective reference frame (when necessary) to reference the objects to the environmental upright. This interpretation is compatible with McMullen and Jolicoeur's (1990) finding that when subjects' heads are tilted, they name familiar objects by primarily using a retinal frame of reference: Subjects might find it easier to reference or match an object to its "normal" environmentally upright memory representation when they themselves are aligned with the object.

One potential difficulty with the above interpretation of Friedman and Hall's (1993) data is that, because the objects had been rotated around an axis that was parallel to their own axis of elongation, it was not possible to attribute the findings solely to the orientation of the objects themselves. That is, if determining the axis of rotation plays a role in the shape identification task, then the results could be due to the fact that the subjects either were or were not aligned with the rotation axis rather than with the objects per se, and when the subjects and the rotation axis were aligned, the computations necessary to determine the rotation axis were facilitated. We felt that if we could contrive a situation in which the subject's head was never aligned with the rotation axis, but angular disparity and distance from the vertical axis were still varied independently, it would provide a better test of the role of the environmental upright in representing the structure and position of the objects themselves. Thus, in Experiment 1, the axis of rotation was the same across all conditions and was not parallel to either the vertical axis or the subjective vertical. Consequently, any effects of distance from the vertical axis must be independent of the influence of the orientation of the rotation axis per se.

We used line drawings of 3-D objects; each had been rotated around the viewer's line of sight (i.e., within the $x-y$ "picture" plane). The angles of rotation were computed by using an (invisible) axis drawn through the center of the middle arm of each object, which extended through the length of the figure (i.e., we used the prin- 
cipal axis of elongation). The leftmost figure in each pair was first rotated $0^{\circ}, 15^{\circ}, 30^{\circ}, 45^{\circ}$, or $60^{\circ}$ from the vertical axis around the viewer's line of sight. We will refer to this distance as the vertical distance factor. Then, the rightmost figure of each pair was rotated an additional $15^{\circ}, 30^{\circ}, 45^{\circ}$, or $60^{\circ}$ from the vertical axis around the viewer's line of sight; the distance between figures will be referred to as the angular disparity factor. The combination of five vertical distances with four angular disparities thus yields the 20 stimulus conditions employed (for examples of the stimulus conditions, see Figure 1). We simply wanted to determine whether there would be a systematic relation between vertical distance and reaction time in addition to the known relation between angular disparity and reaction time. A relation between vertical distance and reaction time has been found for 2-D alphanumeric stimuli by Bundesen, Larsen, and Farrell (1981; see also Cooper \& Shepard, 1973); as mentioned previously, the difficulty with generalizing these findings is that alphanumeric stimuli have welllearned tops. With our unfamiliar 3-D stimuli, in contrast, any effect of vertical distance can be attributed to the fact that subjects must have used the axis of elongation of the objects to reference them to an environmental standard.

It should be noted that when objects that have the same shape are rotated around the viewer's line of sight, they remain physically identical to each other in every respect. However, when objects are rotated with respect to each other in depth, different parts may become visible. Rotating objects in the picture plane is thus useful in the present context, because any differences that are found as a function of distance from the vertical cannot be due to differences in the visibility of their parts.

It should also be noted that the conclusion we wish to make about coding objects with respect to the upright does not rest on whether the influence of vertical distance is additive or multiplicative with angular disparity.
But the interpretation of the influence of the two factors on the slope of the RT function does change as a function of the nature of their relationship (see Judd \& McClelland, 1989 , pp. 239-261, for an especially cogent discussion of this). For example, when we consider the relation between RT and angular disparity as a function of distance from the vertical, then the appropriate equations for the additive and multiplicative models, respectively, are:

$$
\begin{aligned}
\mathrm{RT}= & \left.\beta_{0}+\beta_{1} \text { (Angular Disparity }\right) \\
& +\beta_{2}(\text { Vertical Distance }) \\
\mathrm{RT}= & \beta_{0}+\beta_{1} \text { (Angular Disparity) } \\
& +\beta_{2}(\text { Vertical Distance }) \\
& +\beta_{3} \text { (Interaction) }
\end{aligned}
$$

In both equations, $\beta_{0}$ (the constant) represents the value of the $y$ intercept when the predictor variables equal zero, and $\beta_{2}$ represents the change in the intercept (in milliseconds) as a function of the change in vertical distance (in degrees). That is, in both cases, the intercept is given by $\beta_{0}+\beta_{2}$ (Vertical Distance). Consequently, as long as the $\beta_{2}$ coefficient is reliable in either model, we can say that vertical distance has an influence on encoding the objects. However, in the additive case, $\beta_{1}$ is the slope for the angular disparity function for all of the vertical distances, whereas in the multiplicative case, it is the slope for the disparity function only when vertical distance is zero. Thus, in the multiplicative case, the value of $\beta_{3}$ represents the change in the slope of the disparity function as a function of vertical distance. Consequently, we can say that the influence of vertical distance extends to the rotation process only if $\beta_{3}$ is reliable. ${ }^{1}$

Although no difference has been found for either slopes or intercepts of the mental rotation function when depth rotations have been compared with picture plane rotations (e.g., Metzler \& Shepard, 1974), the relation be-

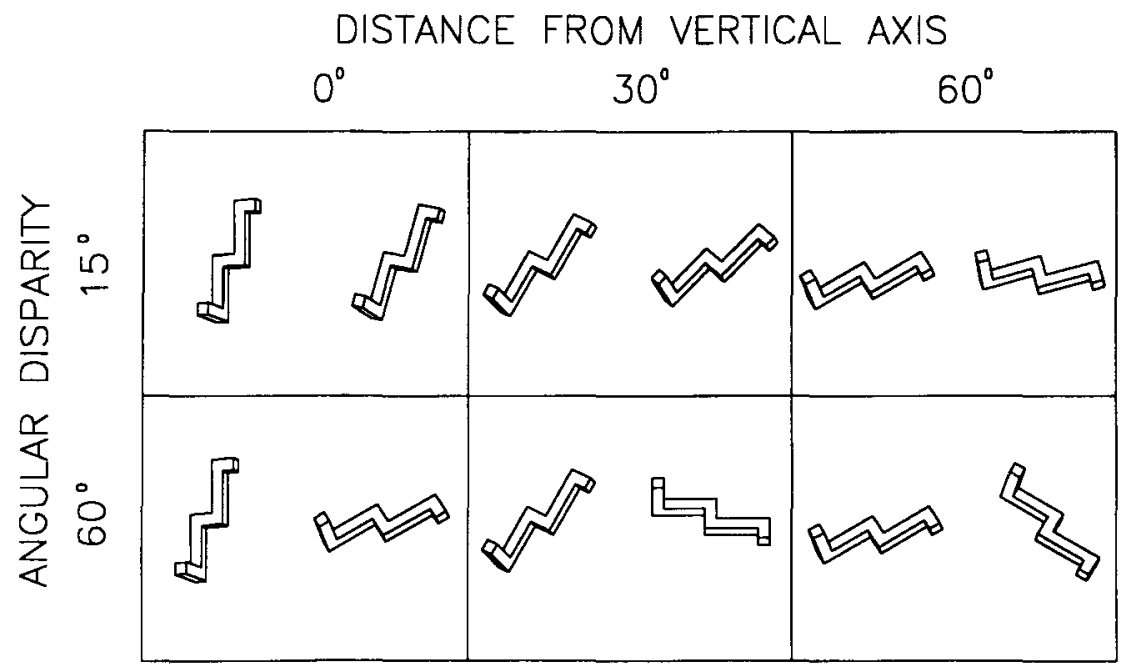

Figure 1. Selected stimulus conditions from Experiment 1 (all rotations around the viewer's line of sight). 
tween the pair as a whole and the vertical upright has not been systematically manipulated in studies that have examined the two types of rotation axes. Thus, in Experiment 2 we replicated the conditions of Experiment 1, but the axis of rotation was oblique with respect to the picture plane, so that the objects were rotated in depth with respect to each other and with respect to the vertical upright. Finally, because of the construction of the stimuli in Experiments 1 and 2, the distance between corresponding ends of the figures increased as both vertical distance and angular disparity increased, and we were concerned that some of our findings might be due to this. We addressed this concern in Experiment 3 and also compared the picture plane and depth conditions directly.

\section{EXPERIMENT 1}

\section{Method}

Stimuli. A single shape and its mirror image (referred to as Shapes A and B) were used to make all the stimulus pairs. By using one shape, we reasoned that the subjects would not require much effort, after practice, to encode the structure of the shape per se. In this sense, the shape itself would be familiar, but the subjects would not get more practice with one orientation than with another.

The shapes were perspective line drawings depicting 3-D objects, which were created by a computer drawing package (AutoCAD 10.0, 1988). Each shape had a long axis with one bend and an arm at each end projecting into the remaining two orthogonal planes (see Figure 1). All interior lines that did not function to depict the 3-D structure of the figures were removed.

Shapes A and B were first completely aligned within the frontal-parallel plane (i.e., no depth was apparent), and four views of each shape were created by rotating each shape around the vertical $(y)$ axis in $90^{\circ}$ steps. Then, to reveal the 3-D structure of the shapes as well as to make sure that the features in each view were as unobscured as possible, we rotated each of the views an additional $40^{\circ}$ either clockwise or counterclockwise around the vertical axis, and then tilted each view "backwards" $10^{\circ}$ around the horizontal $(x)$ axis. The final result was that the four views of each shape were $40^{\circ}, 130^{\circ}, 220^{\circ}$, and $310^{\circ}$ from the starting position. These basic views (four of Shape A and four of Shape B) were used to create all of the stimulus conditions.

Each basic view was rotated clockwise around the frontal-parallel plane (i.e., the $z$-axis) in $15^{\circ}$ steps, up to $120^{\circ}$. The shapes within each view were then paired to create 20 conditions (see Figure 1). The leftmost stimulus in each condition was either vertically oriented (the $0^{\circ}$ condition), or tilted $15^{\circ}, 30^{\circ}, 45^{\circ}$, or $60^{\circ}$ from the upright condition. The rightmost shape was tilted a further $15^{\circ}, 30^{\circ}$, $45^{\circ}$, or $60^{\circ}$ from the leftmost shape. Thus, a pair could be tilted from the $y$-axis from one of five different distances and could have one of four different angular disparities. To resolve the shape identity judgment, the subject merely had to "mentally rotate," around the $z$-axis, the number of degrees that the leftmost shape differed from the rightmost shape, or vice versa, ignoring how much either shape was tilted from the vertical. Across conditions, the stimulus pairs subtended a horizontal visual angle ranging between $9.2^{\circ}$ and $12.5^{\circ}$, and a vertical visual angle between $2.0^{\circ}$ and $5.3^{\circ}$.

Subjects and Design. Six males and 6 females from the University of Alberta undergraduate subject pool participated in the experiment as partial fulfillment of a course requirement. Each subject received 40 practice trials and 160 experimental trials.

The four basic views of each $A$ and $B$ shape could be displayed as "same" (AA and $\mathrm{BB}$ ) or "different" (AB and $\mathrm{BA}$ ) trials, and each of these possibilities was shown in one of the 20 vertical distance and angular disparity conditions described above, for a total of 320 unique stimulus pairs. A given subject saw half of these, which were distributed across conditions as follows: Half of the same and different trials were presented by using two of the four basic views (e.g., $40^{\circ}$ and $220^{\circ}$ ), and the other half were presented by using the other two (e.g., $130^{\circ}$ and $310^{\circ}$ ). Across two pairs of views (e.g., $40^{\circ}$ and $130^{\circ} ; 220^{\circ}$ and $310^{\circ}$ ), each of the AA, BB, AB, and BA pairs was distributed exactly once in each of the 20 experimental conditions. Across two different subjects ( 1 male and 1 female), each of the 320 stimuli was seen exactly once. An equal number of males and females received each counterbalancing condition.

The subjects received 40 practice trials (one same and one different trial for each of the 20 conditions) and then their 160 experimental trials. The experimental trials were distributed across five blocks of 32 trials, with type of trial randomized within a block. In each block, half of the trials were same and half were different, with 4 same and 4 different trials at each angular disparity. No more than 4 trials in a row required the same response. The five distances from the vertical axis were distributed equally and randomly among same and different trials at each angular disparity across the five blocks.

Apparatus and Procedure. A subject was seated approximately $87 \mathrm{~cm}$ in front of a Hewlett-Packard 1304a oscilloscopic display with P15 phosphor; the resolution was set so that lines appeared straight and continuous at all angles. A plotting device, developed by Finley (1985), was used to plot the figures on the oscilloscope during each session. A Zenith 159 computer timed the responses and controlled the display devices.

The subjects placed their heads in a chinrest with two laterally placed head stops, which were used to ensure that they were in a comfortable position but could not tilt their heads. A set of touchplates that were made of two wooden boards with two metal plates across them was on the table in front of the subjects. The subjects rested the heels of their hands on one of the metal plates and their index fingers on raised wooden blocks at the front of the boards. They responded by touching their index fingers to the second metal plate. The subjects used their preferred hand for same responses and the other hand for different responses.

Instructions were read to the subjects, and they were then shown a short demonstration program in which a pair of figures was displayed on the screen. One of the figures was rotated around the appropriate axis in steps, by successive responses on the touchplates, until the orientation for both figures was the same. This was done for two pairs of same and two pairs of different figures. The purpose of the demonstration was to make the concept of mental rotation explicit for the subjects and to give them practice using the touchplates.

After the demonstration, the subjects received 40 practice trials. Each trial began with a short tone, followed .5 sec later by a fixation cross in the center of the screen for $1 \mathrm{sec}$. Then the cross disappeared and the figures were displayed; they remained on the screen until the subject responded. If the response was correct, the figures disappeared and the next trial began. If the response was incorrect, two beeps were sounded and the figures flashed off and then on again, and remained on the screen for 5 additional seconds so that the subject could review the error. Practice trials were followed by 160 experimental trials. The procedure was the same as that for practice trials, except that no feedback was given after incorrect responses. The experimenter remained seated behind the subject throughout the session.

\section{Results}

We first computed the percentage of errors made on same and different trials as a function of condition. For same trials, only the disparity effect was reliable $[F(3,33)=5.31, p<.01]$. Errors increased as a function of the disparity between the objects; the rates were $1.67 \%, 2.08 \%, 4.58 \%$, and $11.25 \%$ as disparities in- 
creased from $15^{\circ}$ to $60^{\circ}$, respectively. Similarly, angular disparity was the only reliable factor for errors on different trials $[F(3,33)=2.90, p<.05]$; the rates were $11.3 \%, 10.4 \%, 15.0 \%$, and $17.1 \%$ as disparities increased from $15^{\circ}$ to $60^{\circ}$. Errors for all same trial conditions are reported in the Appendix. For the remaining analyses, we considered data from only trials on which the subjects responded correctly.

Mean RTs and standard errors from the correct same trials for the 20 angular disparity and distance-fromvertical conditions appear in Table 1. At small angular disparities, distance from the vertical made little difference to the time it took the subjects to discriminate the objects. For example, when the angular disparity between objects was only $15^{\circ}$, RTs were $1,204 \mathrm{msec}$ when the leftmost figure was vertical, and $1,266 \mathrm{msec}$ when the leftmost figure was $60^{\circ}$ from the vertical (a difference of $62 \mathrm{msec}$ ). In contrast, when the angular disparity between objects was $60^{\circ}$, RTs were $1,706 \mathrm{msec}$ when the leftmost figure was vertical, and $2,017 \mathrm{msec}$ when it was $60^{\circ}$ from the vertical (a difference of $311 \mathrm{msec}$ ).

It can also be seen from Table 1 that there are two ways to compute (and to consider) correlations, slopes, and intercepts from the RT data when angular disparity and vertical distance are considered separately. The standard approach is to use the angular disparity between the two objects as one variable and the RT on correct same trials as the other. If this is done separately for each vertical-distance condition (the rows in Table 1), the functions at each distance from the $y$-axis are quite linear, with correlations of $.937, .886, .968, .985$, and .999 for vertical-distance conditions from $0^{\circ}$ to $60^{\circ}$, respectively. Moreover, the slopes of the five different angular disparity functions themselves show a linear increase as a function of increasing distance from the $y$-axis, from $10.4 \mathrm{msec} / \mathrm{deg}$ to $16.6 \mathrm{msec} / \mathrm{deg}[F(1,11)=11.86, p<$ $.005]$. Thus, as distance from the $y$-axis of the leftmost member of each stimulus pair increased, the time to mentally rotate the objects increased at a constant rate. In contrast, the intercepts of the "standard" (row effect) individually computed angular disparity functions were roughly the same at each distance from the $y$-axis.

The second way to compute correlations, slopes, and intercepts is to consider the distance of the leftmost ob- ject from the $y$-axis as one variable, and RTs on correct same trials as the other. Now there are four regression lines-one for each angular disparity (the column effects in Table 1). In this case, the correlations are smaller than those when RTs were regressed against angular disparity $\left(.523, .855, .642\right.$, and .919 at disparities from $15^{\circ}$ to $60^{\circ}$, respectively). However, there was still a reliable linear increase in the slopes themselves, which increased from $1.6 \mathrm{msec} / \mathrm{deg}$ to $6.4 \mathrm{msec} / \mathrm{deg}[F(1,11)=11.85, p<$ $.01]$. Thus, whichever way they are computed, the slope data show that the effect of vertical distance was not the same at each angular disparity (or, equivalently, the effect of angular disparity was not the same at each vertical distance). In addition, for the column effects, there was a reliable linear increase in the intercepts $[F(1,11)=29.26$, $p<.001]$, from $1,143 \mathrm{msec}$ at $15^{\circ}$ to $1,649 \mathrm{msec}$ at $60^{\circ}$.

The joint influence of angular disparity and vertical distance was examined in a repeated measures analysis of variance (ANOVA) on the RT data, in which both variables were treated as quantitative factors; the conclusions reached previously were generally confirmed. The main effect of disparity was reliable $[F(3,33)=32.26, p<$ $.001]$, and $99.6 \%$ of the variance was accounted for by the linear trend $[F(1,11)=46.56, p<.001]$. In addition, the main effect of distance from the vertical axis was also reliable $[F(4,44)=5.70, p<.001]$, and $89.1 \%$ of the variance in this main effect was accounted for by the linear trend $[F(1,11)=14.33, p<.01]$. Most importantly, the interaction between disparity and distance from the vertical was reliable $[F(12,132)=2.10, p<.025]$, as was the linear(disparity) $\times$ linear(distance from vertical) trend $[F(1,11)=11.86, p<.005]$. It is important to note that no other higher order polynomial effects were reliable. It is also important to note that the reliable linear effects of angular disparity, vertical distance, and their interaction in this repeated measures analysis are identical to the effects obtained by testing that the respective regression coefficients across subjects are reliably different from zero (Lorch \& Myers, 1990). Further, a hierarchical regression analysis on the 20 treatment means indicated that when the $80.1 \%[F(1,18)=72.52, p<$ $.001]$ of the total variance attributable to angular disparity was partialed out of the RTs, distance from the vertical accounted for a significant (unique) $9.8 \%$ addi-

Table 1

Reaction Times (in Milliseconds) and Standard Errors, Slopes, and Intercepts as a Function of Angular Disparity and Distance from the Vertical Axis in Experiment 1 (Picture Plane Rotations)

\begin{tabular}{|c|c|c|c|c|c|c|c|c|c|c|c|}
\hline \multirow{3}{*}{$\begin{array}{l}\text { Distance } \\
\text { From } \\
\text { Vertical }\end{array}$} & \multicolumn{8}{|c|}{ Angular Disparity Between Objects } & \multirow[b]{3}{*}{$M$} & \multirow[b]{3}{*}{ Slope } & \multirow[b]{3}{*}{ Intercept } \\
\hline & \multicolumn{2}{|c|}{$15^{\circ}$} & \multicolumn{2}{|c|}{$30^{\circ}$} & \multicolumn{2}{|c|}{$45^{\circ}$} & \multicolumn{2}{|c|}{$60^{\circ}$} & & & \\
\hline & RT & $S E$ & RT & $S E$ & RT & $S E$ & RT & $S E$ & & & \\
\hline $0^{\circ}$ & 1,204 & 101 & 1,323 & 103 & 1,377 & 115 & $1, \overline{706}$ & 162 & 1,403 & 10.4 & 1,013 \\
\hline $15^{\circ}$ & 1,136 & 85 & 1,277 & 106 & 1,739 & 181 & 1,640 & 158 & 1,448 & 13.2 & 954 \\
\hline $30^{\circ}$ & 1.098 & 66 & 1,368 & 80 & 1,451 & 112 & 1,865 & 165 & 1,445 & 15.9 & 850 \\
\hline $45^{\circ}$ & 1,254 & 103 & 1,376 & 125 & 1,735 & 150 & 1,980 & 208 & 1,586 & 16.9 & 952 \\
\hline $60^{\circ}$ & 1,266 & 88 & 1,514 & 126 & 1,745 & 127 & 2,017 & 213 & 1,635 & 16.6 & 1,015 \\
\hline$M$ & 1,191 & & 1,372 & & 1,609 & & 1,841 & & & & \\
\hline Slope & 1.6 & & 3.2 & & 4.9 & & 6.4 & & & & \\
\hline Intercept & 1,143 & & 1,275 & & 1,463 & & 1,649 & & & & \\
\hline
\end{tabular}


tional variance $[F(1,17)=16.44, p<.001]$, and the interaction term accounted for a marginal $1.9 \%$ additional variance $[F(1,16)=3.81, p<.10] .^{2}$

The slope of the angular disparity function over vertical distances $\left(\beta_{1}\right)$ was $14.6 \mathrm{msec} / \mathrm{deg}$, and the slope of the vertical-distance function over angular disparities $\left(\beta_{2}\right)$ was $4.0 \mathrm{msec} / \mathrm{deg}$; the interaction coefficient $\left(\beta_{3}\right)$ was .11 . Because the disparity and distance values were transformed to mean deviations (see note 2), these parameters reflect the values of the regression coefficients when the predictor variables are zero (i.e., at their respective mean values). Thus, as stated previously, a $4.0-\mathrm{msec}$ increase is added to the intercept, and $.11 \mathrm{msec}$ is added to the slope of the angular disparity function as a function of the distance of the pair as a whole from the vertical upright. The latter value is relatively small, and as we will see in Experiment 3 , it depends upon the overall configuration of the stimuli.

\section{Discussion}

As we had hoped, there was an effect of vertical distance in addition to the effect of angular disparity between the objects. Because the axis of rotation was the same across all angular disparity and vertical distance conditions, and was not parallel to either the long axis of the objects or the subjective vertical, the influence of vertical distance on RTs could not have been due to the necessity of determining the axis of rotation, as it might have been in our other studies (Friedman \& Hall, 1993). Consequently, we believe that the main effect of vertical distance (i.e., the $4.0-\mathrm{msec}$ increase in RT as a function of vertical distance) reflects the time it takes subjects to either normalize or reference 3-D stimuli to the vertical axis. Although we do not address this distinction in the present study, it has important implications with respect to what is ultimately represented (e.g., an upright pair of objects vs. tilted objects with a "transformation list") and, therefore, has implications with respect to subsequent processing. Further, because the objects were unfamiliar and were presented equally often at all tested orientations, we believe that normalizing or referencing the stimuli with respect to the vertical axis is a fundamentally perceptual process that takes place during the course of 3-D object identification (see also Jolicoeur, 1985; McMullen \& Jolicoeur, 1990).

The main difficulty with this interpretation is that rotations of 3-D objects in the picture plane are like rotations of 2-D alphanumeric stimuli; even though stimulus objects that have been rotated in the picture plane are depicted as having three dimensions, they may be encoded, rotated, and compared without regard to their 3-D properties. However, Jolicoeur, Regehr, Smith, and Smith (1985) showed that the 3-D appearance of an object matters, even for picture plane rotations: 3-D stimuli took longer to rotate the same distance around the picture plane than the identical, filled-in (so as to remove the 3-D appearance), 2-D counterparts. Of necessity, of course, Jolicoeur et al. (1985) could not compare rotations of 2- versus 3-D stimuli in depth. And although Metzler and Shepard (1974) did compare rotations of the same 3-D stimuli in depth and in the picture plane and found no difference in rotation rates, they did not systematically manipulate the relation between the stimuli and the vertical (or any other) axis. Further, although we found an influence of vertical distance when the stimuli themselves had been rotated in depth with respect to each other (Friedman \& Hall, 1993), in those studies, the distance between the long axis of the stimuli and the vertical axis was achieved by a rotation of the pair as a whole around the subject's line of sight. In Experiment 2 , we examined the effects of distance from the vertical when the distance between the objects with respect to each other as well as with respect to the vertical axis was achieved via a rotation in depth.

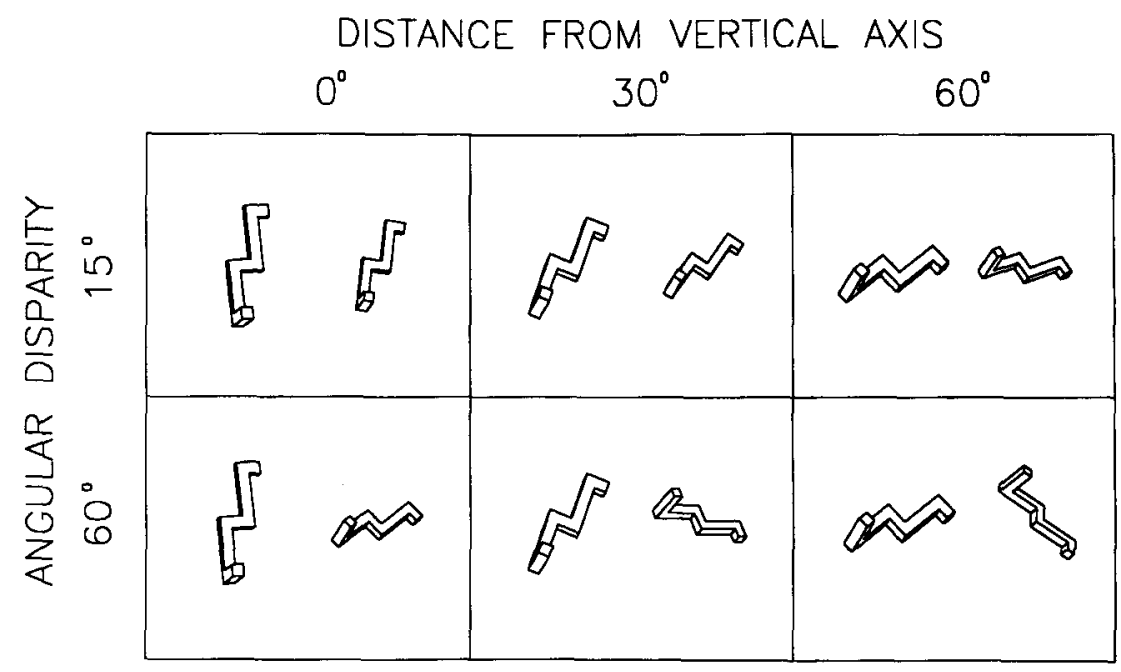

Figure 2. Selected stimulus conditions from Experiment 2 (all rotations around an axis that was oblique with respect to the picture plane). 


\section{EXPERIMENT 2}

\section{Method}

Twelve subjects ( 6 males and 6 females) were recruited from the University of Alberta department of psychology subject pool to participate in partial fulfillment of a course requirement. They were assigned to conditions with the same procedure as that used in Experiment 1.

The apparatus, procedure, and design were identical in every respect to those of the previous study. We created a new set of stimuli that were identical to the stimuli in Experiment 1, pair for pair, except that the new stimuli were drawn as if a vertical axis had been placed equidistant between the two figures, and the entire plane that the figures were drawn on was rotated $37^{\circ}$ around that axis (see Figure 2). Thus, the axis around which the figures were rotated into congruence with respect to each other as well as with respect to the vertical axis was oblique with respect to the picture plane; consequently, both rotations had to take place in depth. The new stimulus pairs subtended a horizontal visual angle ranging between $7.6^{\circ}$ and $9.9^{\circ}$ and a vertical visual angle between $3.6^{\circ}$ and $4.7^{\circ}$. Note that creating depth by rotating the entire plane in this way effects a change in the size of the "farther" stimulus (see Bundesen et al., 1981). This issue will be addressed in the General Discussion.

\section{Results}

For errors on same and different trials, there were, again, main effects of only angular disparity $[F(3,33)=$ $5.15, p<.005$, and $F(3,33)=3.29, p<.05$, respectively]. The error rates for angular disparities from $15^{\circ}$ to $60^{\circ}$ were $1.3 \%, 3.3 \%, 5.4 \%$, and $10.4 \%$, respectively, for same trials, and $9.2 \%, 5.4 \%, 10.0 \%$, and $11.7 \%$ for different trials. Errors for all the same trial conditions are reported in the Appendix.

RTs on correct same trials were analyzed in the same manner as that used in Experiment 1, and the results were basically identical. Table 2 shows the RT data as a function of both angular disparity and distance from the vertical. Clearly, the farther the stimuli were from the vertical, the longer it took to respond, especially at the larger angular disparities. When the angular disparity functions were considered individually (i.e., the row effects), the effect of angular disparity was strong and linear at each distance from the vertical axis, with correlations of $.998, .989, .883, .993$, and .997 , for the distances from $0^{\circ}$ to $60^{\circ}$, respectively. Again, there was a linear increase in the slopes themselves, from $20.5 \mathrm{msec} / \mathrm{deg}$ to $31.7 \mathrm{msec} / \mathrm{deg}[F(1,11)=14.86, p<.01]$. There was no systematic effect of vertical distance on the intercepts of the individually computed angular disparity functions. Similar to Experiment 1, the correlations were not as strong for each of the four angular disparity conditions $\left(.224, .625, .680\right.$, and .780 for the disparities from $15^{\circ}$ to $60^{\circ}$, respectively); nevertheless, for the data considered in this way, the slopes of the functions relating RT to distance from the $y$-axis again increased linearly [from $0.8 \mathrm{msec} / \mathrm{deg}$ to $9.3 \mathrm{msec} / \mathrm{deg} ; F(1,11)=14.86, p<$ .01 ]. There was also a reliable linear increase in the (column effect) intercepts $[F(1,11)=10.21, p<.01]$.

The observations regarding the slopes were again corroborated by ANOVA. The main effect of disparity was reliable $[F(3,33)=12.95, p<.001]$, and $99.0 \%$ of the variance was accounted for by the linear trend $[F(1,11)=$ $16.83, p<.01]$. Similarly, distance from the $y$-axis was reliable $[F(4,44)=6.85, p<.001]$, with $62.2 \%$ of the variance accounted for by the linear trend $[F(1,11)=9.19$, $p<.025]$. And although there was no overall interaction between disparity and vertical distance, the linear(disparity) $\times$ linear(vertical distance) interaction was again reliable $[F(1,11)=14.86, p<.025]$. It is important to note that these findings indicate that all three regression coefficients were reliably greater than zero. There was also a reliable quadratic component in the verticaldistance effect $[F(1,11)=7.20, p<.025]$, which accounted for $20.0 \%$ of the variance.

A hierarchical regression analysis on RTs from the 20 angular disparity and distance-from-vertical conditions showed that angular disparity accounted for $82.5 \%$ of the variance $[F(1,18)=84.86, p<.001]$, vertical distance accounted for an additional (unique) $6.1 \%$ of the variance $[F(1,17)=9.01, p<.001]$, and the interaction term accounted for a marginal additional $2.4 \%[F(1,16)=$ $4.36, p<.10]$. Keeping in mind that the parameters of the regression equation reflect the values at the means of the predictor variables (see note 2 ), the slope of the angular disparity function across vertical distances $\left(\beta_{1}\right)$ was $23.2 \mathrm{msec} / \mathrm{deg}$, the slope of the vertical distance function across disparities $\left(\beta_{2}\right)$ was $5.0 \mathrm{msec} / \mathrm{deg}$, and the interaction coefficient $\left(\beta_{3}\right)$ was .19.

Table 2

Reaction Times (in Milliseconds) and Standard Errors, Slopes, and Intercepts as a Function of Angular Disparity and Distance from the Vertical Axis in Experiment 2 (Depth Rotations)

\begin{tabular}{|c|c|c|c|c|c|c|c|c|c|c|c|}
\hline \multirow{3}{*}{$\begin{array}{c}\text { Distance } \\
\text { From } \\
\text { Vertical }\end{array}$} & \multicolumn{8}{|c|}{ Angular Disparity Between Objects } & \multirow[b]{3}{*}{$M$} & \multirow[b]{3}{*}{ Slope } & \multirow[b]{3}{*}{ Intercept } \\
\hline & \multicolumn{2}{|c|}{$15^{\circ}$} & \multicolumn{2}{|c|}{$30^{\circ}$} & \multicolumn{2}{|c|}{$45^{\circ}$} & \multicolumn{2}{|c|}{$60^{\circ}$} & & & \\
\hline & RT & $S E$ & RT & $S E$ & RT & $S E$ & RT & $S E$ & & & \\
\hline $0^{\circ}$ & 1,792 & 203 & 2,052 & 223 & 2,362 & 377 & 2,715 & 387 & 2,230 & 20.5 & 1,461 \\
\hline $15^{\circ}$ & 1,626 & 128 & 1,965 & 238 & 2,164 & 297 & 2,619 & 472 & 2,094 & 21.2 & 1,300 \\
\hline $30^{\circ}$ & 1,730 & 154 & 2,287 & 543 & 2,168 & 214 & 2,548 & 354 & 2,183 & 15.6 & 1,600 \\
\hline $45^{\circ}$ & 1,850 & 241 & 2,113 & 298 & 2,591 & 259 & 3,045 & 567 & 2,400 & 27.1 & 1,384 \\
\hline $60^{\circ}$ & 1,739 & 228 & 2,240 & 281 & 2,625 & 306 & 3,197 & 550 & 2,451 & 31.7 & 1,261 \\
\hline$M$ & 1,748 & & 2,132 & & 2,382 & & 2,825 & & & & \\
\hline Slope & 0.79 & & 3.5 & & 6.4 & & 9.3 & & & & \\
\hline Intercept & 1,724 & & 2,027 & & 2,191 & & 2,546 & & & & \\
\hline
\end{tabular}




\section{Discussion}

The data from Experiments 1 and 2 indicate that, in addition to the angular disparity between two objects, the distance between the objects and the upright influences the time it takes subjects to determine whether the objects have the same shape. The effect occurs whether vertical distance is depicted around the viewer's line of sight or in depth (with respect to the viewer) around an axis that was oblique with respect to the line of sight. However, as we noted earlier, because the left and right stimuli in a pair were centered to the left and right of the screen, the distance between their respective ends increased as a function of the angular disparity between the objects as well as of the distance of their ends from the vertical. Because finding corresponding parts or ends is an important component of the slope in the overall angular disparity function (Just \& Carpenter, 1976, 1985), we wanted to make this part of the task easier in Experiment 3. Thus, we kept the bottom of each stimulus in a pair together as their tops were rotated away from each other and as the pair as a whole was rotated away from the vertical axis. In this way, it was always clear which ends of the stimuli were to be matched.

It should be noted that, by keeping the bottom ends together for pairs rotated within the picture plane, the distances between the ends of the objects in each angular disparity condition were physically identical when they were rotated by different amounts from the vertical axis, whereas in Experiment 1 they were not (cf. Figures 1 and 3). Consequently, for the picture plane pairs in Experiment 3 , even though one set of corresponding ends of the figures becomes increasingly distant as a function of angular disparity, the ends for a given angular disparity condition (e.g., $60^{\circ}$ ) are equidistant with respect to each other across the different vertical-distance conditions. Thus, any effect of vertical distance cannot be due to differences in subjects' difficulty with finding corre- sponding parts. Moreover, differences found as a function of vertical distance should not be due to the nature of the eye movements that have to be made as a function of the different conditions because of the arrangement of the stimuli per se. The literature on the ballistic nature of saccadic eye movements indicates no difference in speed or duration between horizontal (left-right), vertical (updown), or oblique saccades (Taumer, Lemb, \& Namislo, 1976, p. 172; Yarbus, 1967, p. 142), although latencies of upward saccades are shorter than downward saccades, with left-right latencies in between (so that the latency differences average out; Heywood \& Churcher, 1980).

For the depth pairs in Experiment 3, of course, even though the bottom ends of the stimuli were kept together, since the entire plane was rotated in depth around the $y$-axis, corresponding ends of the stimuli still become physically farther apart as a function of distance from the vertical or from each other. But the corresponding ends of the stimuli used in Experiment 3 were still easier to determine than they were for the depth pairs of Experiment 2 (cf. Figures 2 and 4). Thus, finding corresponding parts should not make an important contribution to either the depth or picture plane condition in Experiment 3.

We also noted that the overall RTs in Experiment 2 were longer than the RTs in Experiment 1 (see Tables 1 and 2), although in the original mental rotation studies (Metzler \& Shepard, 1974; Shepard \& Metzler, 1971) there were no differences in either slope or intercept of the RT function as a function of whether 3-D stimuli had been rotated in depth or in the picture plane. However, neither these authors nor others who have varied the axis of rotation (e.g., Parsons, 1987) has systematically varied the alignment of the pairs with respect to the vertical upright (or with respect to any other axis, for that matter). In Experiment 3, we compared picture plane and depth rotations of the same stimuli directly.

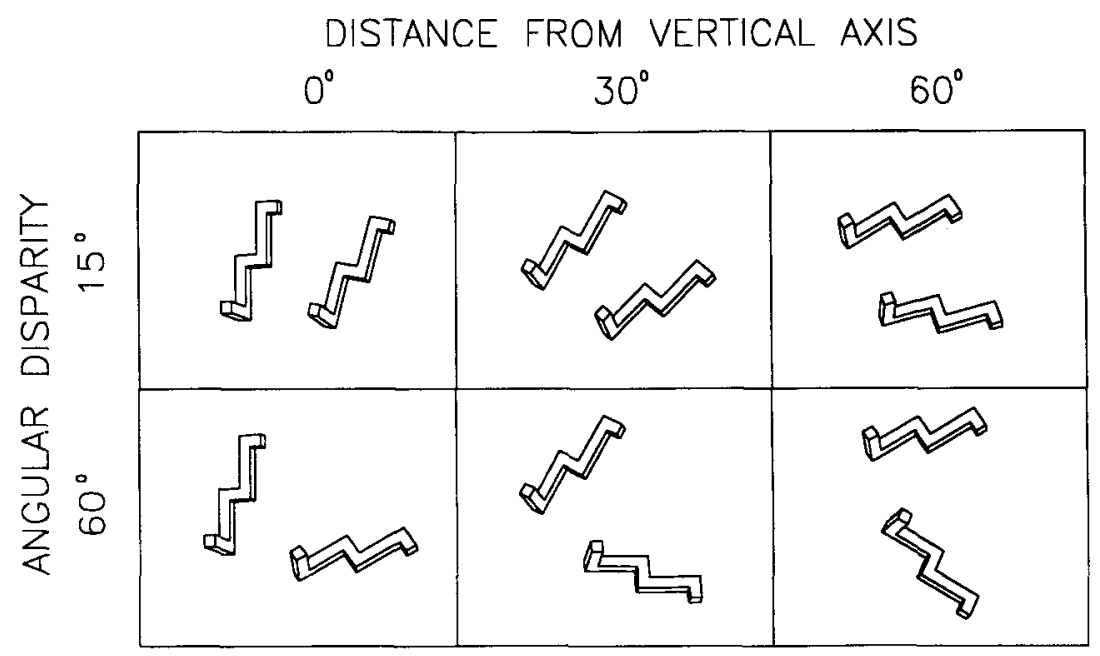

Figure 3. Selected stimulus conditions from Experiment 3, picture plane condition. 


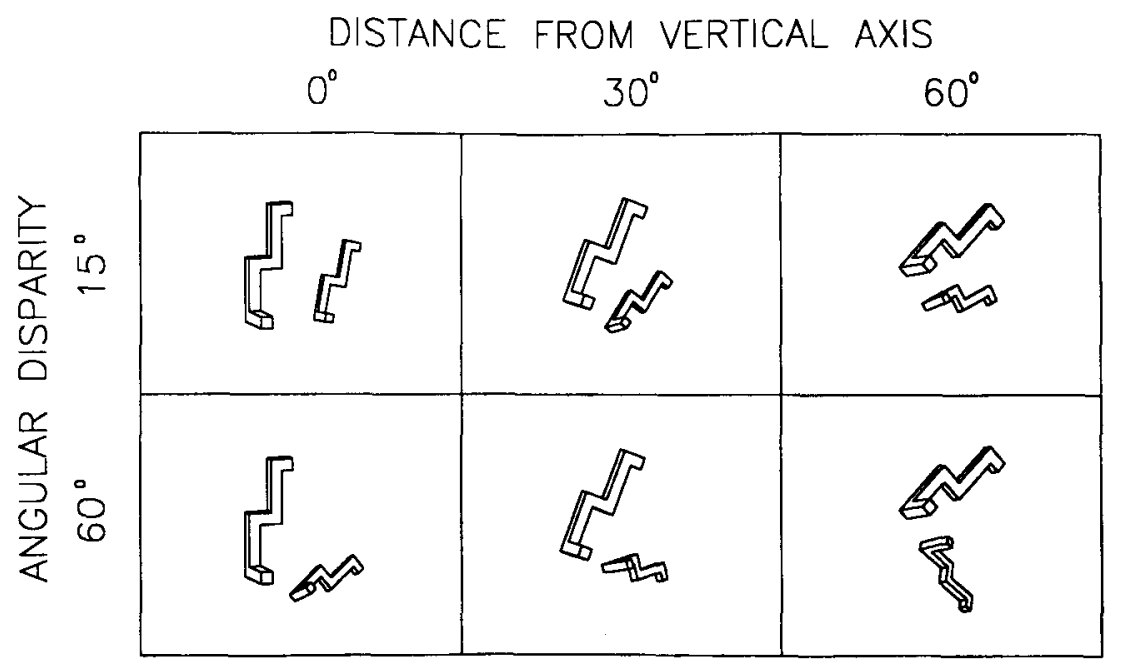

Figure 4. Selected stimulus conditions from Experiment 3, depth condition.

\section{EXPERIMENT 3}

\section{Method}

Subjects. Twelve volunteers ( 6 male and 6 female) from the University of Alberta were recruited; they were paid $\$ 6.00$ for their participation.

Stimuli and Design. To determine whether the findings of the first two experiments were due to the arrangement of the stimuli within a pair, the stimuli in each pair were "pinned" at one end, when they were rotated apart from each other. In this way, it should not have been as difficult to determine corresponding parts (see Figures 3 and 4). However, the conditions were essentially the same as those in Experiments 1 and 2. For the picture plane condition, for example, there were 20 conditions formed by the factorial combination of four angular disparities between objects $\left(15^{\circ}, 30^{\circ}, 45^{\circ}\right.$, and $\left.60^{\circ}\right)$ and five distances between the leftmost object in a pair and the vertical upright $\left(0^{\circ}, 15^{\circ}, 30^{\circ}, 45^{\circ}\right.$, and $\left.60^{\circ}\right)$. There were 20 depth conditions that were identical to the picture plane conditions. Each depth pair was formed from the corresponding picture plane pair as before, except that, to make the depth condition, the picture plane pairs were redrawn as if the plane of projection had been rotated in depth by $45^{\circ}$ around a vertical axis that was centered between the two figures (as compared with $37^{\circ}$ in Experiment 2). The picture plane pairs subtended a horizontal visual angle ranging between $5.9^{\circ}$ and $7.9^{\circ}$ and a vertical visual angle between $4.6^{\circ}$ and $9.3^{\circ}$. The depth pairs subtended a horizontal visual angle ranging between $4.3^{\circ}$ and $5.9^{\circ}$ and a vertical visual angle between $5.6^{\circ}$ and $6.3^{\circ}$.

The subjects saw one block of 40 practice trials and eight blocks of 40 experimental trials, for a total of 320 experimental trials. Half of the trials in each block required a "same" response and half required a "different" response; half of each type of response were trials that depicted picture plane pairs, and the other half depicted depth pairs. For each 10 picture plane and depth condition trials per "same" or "different" response in a block, there were two instances for each of the distances from the vertical, and each of these were from a different angular disparity condition. Across two blocks, all 4 (angular disparity) $\times 5$ (distance from vertical) $\times 2$ (response types) $\times 2$ (plane of rotation) conditions were seen exactly once; trials were randomized within blocks for each subject. Across 4 subjects ( 2 males and 2 females), all the various stimulus pairs used in the experiment (e.g., the four views of each stimulus shape, whether it was on the left or the right of a pair, etc.) were seen exactly once.
Apparatus and Procedure. Except for demonstrating both the picture plane and depth conditions during the instructions, the apparatus and procedure were identical to those used in the first two experiments.

\section{Results}

Once again, the only reliable effect for the error data on same trials was that of angular disparity. Error rates on same trials for disparities between $15^{\circ}$ and $60^{\circ}$ were $1.5 \%, 2.1 \%, 5.6 \%$, and $6.3 \%$, respectively $[F(3,33)=$ $5.03, p<.01]$. For different trials, angular disparity was not reliable, but more errors were made on depth pairs $(7.7 \%)$ than on picture plane pairs $[4.7 \% ; F(1,11)=$ $6.33, p<.05]$. No other effects were reliable. Error data for all the same trial conditions are reported in the Appendix.

The picture plane and depth conditions were first analyzed separately, for comparison with the first two experiments. The data are given in Tables 3 and 4 . For the picture plane condition, the correlations between angular disparity and RT (row effects) were $.941, .951, .878$, .934 , and .975 for vertical distances from $0^{\circ}$ to $60^{\circ}$. The increase in slopes of the individual functions, from $9.5 \mathrm{msec} / \mathrm{deg}$ to $11.0 \mathrm{msec} / \mathrm{deg}$, was unreliable, and there was also no difference among the intercepts. The correlations for the column effects were $.808, .800,-.145$, and .944 for angular disparities between $15^{\circ}$ and $60^{\circ}$, and, again, the increase in slopes from $2.9 \mathrm{msec} / \mathrm{deg}$ to $4.7 \mathrm{msec} / \mathrm{deg}$ was unreliable. However, as in Experiment 1, the linear increase in the intercepts was reliable $[F(1,11)=24.58, p<.001]$.

For the depth pairs, the correlations for the different angular disparity functions (row effects) were $.989, .947$, $.959, .723$, and .967 , and although the slopes increased from 11.3 to $22.9 \mathrm{msec} / \mathrm{deg}$, the slope increase and the differences among the intercepts were unreliable. The correlations for the column effects were $.868, .660, .794$, and .653, and, again, the increase in slopes (from 3.2 to $8.7 \mathrm{msec}$ ) was unreliable. But, in a replication of Ex- 
Table 3

Reaction Times (in Milliseconds) and Standard Errors, Slopes, and Intercepts as a Function of Angular Disparity and Distance from the Vertical Axis in Experiment 3 (Picture Plane Rotations)

\begin{tabular}{|c|c|c|c|c|c|c|c|c|c|c|c|}
\hline \multirow{3}{*}{$\begin{array}{l}\text { Distance } \\
\text { From } \\
\text { Vertical }\end{array}$} & \multicolumn{8}{|c|}{ Angular Disparity Between Objects } & \multirow[b]{3}{*}{$M$} & \multirow[b]{3}{*}{ Slope } & \multirow[b]{3}{*}{ Intercept } \\
\hline & \multicolumn{2}{|c|}{$15^{\circ}$} & \multicolumn{2}{|c|}{$30^{\circ}$} & \multicolumn{2}{|c|}{$45^{\circ}$} & \multicolumn{2}{|c|}{$60^{\circ}$} & & & \\
\hline & RT & $S E$ & RT & $S E$ & RT & $S E$ & RT & $S E$ & & & \\
\hline $0^{\circ}$ & 1,045 & 113 & 1,260 & 169 & 1,453 & 166 & 1,453 & 158 & 1,303 & 9.5 & 948 \\
\hline $15^{\circ}$ & 1,170 & 138 & 1,255 & 133 & 1,484 & 164 & 1,498 & 144 & 1,352 & 8.1 & 1,049 \\
\hline $30^{\circ}$ & 1,094 & 89 & 1,373 & 180 & 1,308 & 154 & 1,503 & 180 & 1,319 & 7.7 & 1,029 \\
\hline $45^{\circ}$ & 1,241 & 135 & 1,411 & 204 & 1,399 & 147 & 1,624 & 200 & 1,419 & 7.6 & 1,135 \\
\hline $60^{\circ}$ & 1,224 & 110 & 1,360 & 171 & 1,463 & 173 & 1,740 & 222 & 1,447 & 11.0 & 1,034 \\
\hline$M$ & 1,155 & & 1,332 & & 1,421 & & 1,564 & & & & \\
\hline Slope & 2.9 & & 2.4 & & -0.4 & & 4.7 & & & & \\
\hline Intercept & 1,069 & & 1,261 & & 1,434 & & 1,424 & & & & \\
\hline
\end{tabular}

Table 4

Reaction Times (in Milliseconds) and Standard Errors, Slopes, and Intercepts as a Function of Angular Disparity and Distance from the Vertical Axis in Experiment 3 (Depth Rotations)

\begin{tabular}{|c|c|c|c|c|c|c|c|c|c|c|c|}
\hline \multirow{3}{*}{$\begin{array}{l}\text { Distance } \\
\text { From } \\
\text { Vertical }\end{array}$} & \multicolumn{8}{|c|}{ Angular Disparity Between Objects } & \multirow[b]{3}{*}{$M$} & \multirow[b]{3}{*}{ Slope } & \multirow[b]{3}{*}{ Intercept } \\
\hline & \multicolumn{2}{|c|}{$15^{\circ}$} & \multicolumn{2}{|c|}{$30^{\circ}$} & \multicolumn{2}{|c|}{$45^{\circ}$} & \multicolumn{2}{|c|}{$60^{\circ}$} & & & \\
\hline & RT & $S E$ & RT & $S E$ & RT & $S E$ & RT & $S E$ & & & \\
\hline $0^{\circ}$ & 1,148 & 155 & 1,390 & 187 & 1,499 & 181 & 1,673 & 282 & 1,427 & 11.2 & 1,006 \\
\hline $15^{\circ}$ & 1,095 & 139 & 1,184 & 97 & 1,313 & 138 & 1,671 & 283 & 1,316 & 12.4 & 852 \\
\hline $30^{\circ}$ & 1,250 & 136 & 1,291 & 125 & 1,535 & 194 & 1,828 & 257 & 1,476 & 13.2 & 982 \\
\hline $45^{\circ}$ & 1,264 & 130 & 1,496 & 271 & 1,819 & 324 & 1,585 & 205 & 1,541 & 8.6 & 1,220 \\
\hline $60^{\circ}$ & 1,300 & 190 & 1,538 & 251 & 1,765 & 232 & 2,371 & 276 & 1,743 & 22.9 & 884 \\
\hline$M$ & 1,211 & & 1,380 & & 1,586 & & 1,825 & & & & \\
\hline Slope & 3.2 & & 4.1 & & 6.9 & & 8.7 & & & & \\
\hline Intercept & 1,116 & & 1,258 & & 1,379 & & 1,563 & & & & \\
\hline
\end{tabular}

periment 2, the increase in intercepts from 1,116 to $1,563 \mathrm{msec}$ was reliable $[F(1,11)=6.72, p<.025]$.

It appears that the main difference between the first two experiments and the present experiment was a loss of the interactive effect of angular disparity and vertical distance on the slopes of the functions; this impression was confirmed in separate angular disparity $\times$ vertical distance ANOVAs on correct RTs from same trials for the picture plane and depth conditions. For the picture plane condition, the main effect of angular disparity was reliable $[F(3,33)=21.33, p<.001]$, and the linear trend accounted for $98.5 \%$ of the variance $[F(1,11)=37.65$, $p<.001]$. The main effect of vertical distance was also reliable $[F(4,44)=4.29, p<.005]$, and the linear trend accounted for $80.5 \%$ of the variance $[F(1,11)=8.50, p<$ $.025]$. Unlike that in Experiment 1, the interaction was not reliable, nor was the linear component of the interaction or any higher order polynomials. Similarly, for the depth pairs, the main effect of disparity was reliable $[F(3,33)=21.16, p<.001]$, and the linear trend accounted for $99.4 \%$ of the variance $[F(1,11)=31.11, p<$ $.001]$. The main effect of vertical distance was also reliable $[F(4,44)=9.82, p<.001]$, and the linear trend accounted for $44.1 \%$ of the variance $[F(1,11)=18.18, p<$ $.001]$. The quadratic component of the vertical-distance effect was also reliable $[F(1,11)=10.41, p<.01]$, accounting for $20.1 \%$ of the variance. But unlike Experiment 2 , neither the distance $\times$ disparity interaction nor its linear trend was reliable.
A hierarchical regression on the 20 means from the picture plane condition showed that angular disparity accounted for $77.0 \%$ of the variance $[F(1,18)=60.37, p<$ $.001]$, vertical distance accounted for an additional (unique) $9.0 \%[F(1,17)=10.84, p<.01]$, and the interaction term did not reliably account for any additional variance. The slope of the angular disparity function across vertical distances $\left(\beta_{1}\right)$ was $8.8 \mathrm{msec} / \mathrm{deg}$, and the slope of the vertical distance function across disparities $\left(\beta_{2}\right)$ was $2.4 \mathrm{msec} / \mathrm{deg}$. Similarly, a regression on the 20 means from the depth condition showed that angular disparity accounted for $60.2 \%$ of the variance $[F(1,18)=$ $27.21, p<.001]$, vertical distance accounted for an additional (unique) $16.9 \%[F(1,17)=12.48, p<.01]$, and the interaction term was unreliable. The slope of the angular disparity function across vertical distances $\left(\beta_{1}\right)$ was $13.7 \mathrm{msec} / \mathrm{deg}$, and the slope of the vertical-distance function across disparities $\left(\beta_{2}\right)$ was $5.7 \mathrm{msec} / \mathrm{deg}$.

The most unique aspect of Experiment 3 lies in the comparisons it allows between rotations in depth and rotations in the picture plane. Thus, the correct RTs from same trials were analyzed in a repeated measures ANOVA with factors of angular disparity, distance from the vertical axis, and type of rotation (picture plane or depth). We will discuss only those effects that are not redundant with previous analyses.

The main effect of plane of rotation $[F(1,11)=11.16$, $p<.01]$ indicated that rotations in depth took longer than rotations in the frontal-parallel plane $(1,501 \mathrm{vs.} 1,368 \mathrm{msec}$, 
respectively). The interaction between angular disparity and plane of rotation was reliable $[F(3,33)=3.91, p<$ $.025]$; the linear(disparity) $\times$ plane component of the interaction $[F(1,11)=7.93, p<.025]$, which accounted for $87.5 \%$ of the variance, indicated that the slope of the RT function for angular disparity was greater for stimuli that had been rotated in depth than it was for stimuli that had been rotated within the frontal-parallel plane (13.7 vs. $8.8 \mathrm{msec} / \mathrm{deg}$ ). RTs for depth rotations were 1,211 , $1,380,1,586$, and $1,825 \mathrm{msec}$ for angular disparities between $15^{\circ}$ and $60^{\circ}$, respectively, whereas RTs were 1,155 , $1,332,1,421$, and $1,564 \mathrm{msec}$ for picture plane rotations.

Similarly, the interaction between vertical distance and plane of rotation $[F(4,44)=5.42, p<.001]$ was reliable, as was the linear (distance) $\times$ plane component $[F(1,11)=$ $8.12, p<.025]$, which accounted for $45.0 \%$ of the variance. This interaction showed that the effect of distance from the vertical was greater for depth pairs (RTs were $1,427,1,316,1,476,1,541$, and $1,743 \mathrm{msec}$ for vertical distances between $0^{\circ}$ and $60^{\circ}$; slope $=5.7 \mathrm{msec}$ ) than for picture plane pairs (RTs were 1,303, 1,352, 1,319, 1,419, and $1,447 \mathrm{msec}$; slope $=2.4 \mathrm{msec}$ ).

\section{GENERAL DISCUSSION}

When subjects compared pairs of unfamiliar 3-D objects for the purpose of making shape identity judgments, there was an increase in the time it took them to do so as a function of both the angular disparity between the objects and the distance between an axis drawn through the longest extent of the objects and the vertical axis. When they did not have to search for corresponding ends of the stimuli (Experiment 3), the angular disparity factor and the vertical-distance factor were additive; when corresponding ends of the figures were less evident, as they were in the first two experiments, the factors interacted. Although Just and Carpenter (1976) did not vary vertical distance systematically, they did find that the distance between corresponding ends, which generally increases with angular disparity, affects the component of the overall slope that is related to the search process. In our first two experiments, the distance between corresponding ends increased with both angular disparity and vertical distance, so it is not surprising that these factors interacted to produce an increase in the slopes of the family of RT functions that describe the data. Equally, it is not surprising that the interactive effect of these two factors disappeared when finding the corresponding ends was less problematic, as in Experiment 3.

It should be noted that the effect of vertical distance was consistently smaller, in terms of variance accounted for, than the effect of angular disparity. One important reason for this is that in the real world, subjects hardly ever compare two objects to determine whether they have identical shapes, so the process they use to do so in the laboratory is deliberate, strategic, and relatively lengthy. In contrast, subjects may normalize stimuli with respect to the vertical axis as part of their usual object recogni- tion process. This normalization would therefore be relatively automatic and efficient. The error data in all three experiments support this interpretation because neither vertical distance nor any of its interactions was reliable, whereas the effect of angular disparity was always reliable for errors.

The increase in RT as a function of vertical distance was obtained whether the objects had been rotated around the viewer's line of sight or in depth around an axis that was oblique with respect to the line of sight. Further, the effects on RTs of angular disparity between objects and of vertical distance were both magnified more when the figures were rotated in depth than when they had been rotated around the viewer's line of sight. There are many possible reasons for the fact that depth rotations were slower than rotations in the picture plane (see Metzler \& Shepard, 1974). For example, when objects have been rotated in depth with respect to each other around an axis within the picture plane (e.g., $x$ or $y$ ), they may have different visible parts that need to be reconciled as corresponding, and parts of the objects may mentally "disappear" and "reappear" during the rotation process. Neither of these possibilities is likely to underlie the difference between picture plane and depth rotations in the present case, however, because the entire $x-y$ plane was, in effect, rotated around the $y$-axis to achieve the rotation in depth. Thus, the same parts were visible in both objects, and the axis of rotation did not result in the parts' becoming "hidden" as the objects were mentally rotated into congruence. Still, these factors may be important for depth rotations more generally.

A more likely possibility for explaining the increased time required to process depth rotations in Experiments 2 and 3 is the fact that, in these experiments, the figure that was "farther away" was necessarily depicted as being smaller in size-again, because the depth rotation was achieved by effectively rotating the entire plane in which the figures were drawn. We created the depth pairs this way precisely so that differences in visibility of corresponding parts would not be a factor in the results. In contrast, in experiments in which picture plane and depth rotations were found to have equally sloped rotation functions (e.g., Metzler \& Shepard, 1974), depth conditions were constructed by rotating the stimuli around the vertical axis, so that the relative sizes of the two objects were the same, but different parts were visible.

Many authors have shown that normalizing stimuli for size takes time, even when size is an irrelevant dimension (Besner \& Coltheart, 1976; Bundesen \& Larsen, 1975; Bundesen et al., 1981; Dixon \& Just, 1978; Sekuler $\&$ Nash, 1972). For example, Sekuler and Nash showed that size normalization and mental rotation were independent processes. Bundesen et al. did too, and they went on to argue convincingly that disparities of size were visually resolved as differences in depth (even for their 2-D alphanumeric stimuli), and that mental transformation times were directly proportional to these depth differences. The data from the present studies ex- 
tend Bundesen et al.'s data to unfamiliar 3-D stimuli, and thus, they are relevant to the mental transformation literature more generally. Further research with different kinds of depth rotations should help establish whether the effect of plane of rotation in the present experiments is due to a size normalization process that occurs as a function of the particular type of depth rotation used, or to the depth rotation per se.

With respect to the mechanism underlying the effect of vertical distance on encoding times, at this point we have no way to distinguish the possibility that the subjects performed another type of normalization process, in which they actually mentally rotated the pair of objects to the upright, from the possibility that they simply performed computations that merely referenced the representations to the upright. The latter computations might become more difficult or numerous as the pair was depicted farther from the upright, and in this way they could account for an increase in reaction time. As mentioned previously, the distinction between these two types of processes has interesting and important implications with respect to what is ultimately represented; thus, determining whether objects are normalized or referenced to the upright and exactly how this is done is also an avenue for further research.

When subjects know which ends of the stimuli correspond, there are several ways of combining the two variables additively, and these differ as a function of what we assume subjects are doing to perform the task; a priori, one method would not appear to be any more appropriate than another. For example, it is possible that subjects normalize or reference each figure individually to the upright and then compare the figures, so RT is actually a function of total distance to the vertical axis. This total would reflect the angular disparity between the objects, of course, but not in the way that angular disparity is usually conceptualized. Alternatively, the appropriate combination of the factors might reflect two separate processes: First, subjects normalize or reference the pair as a whole to the upright (e.g., by using the object closest to the upright as an anchor) and only then do they transform and compare the objects with each other. Previous research that has shown that simple size and orientation transformations occur as separate, additive processes supports the latter idea (e.g., Bundesen et al., 1981).

Because we did not implement a head-tilt condition in any of the present experiments, we cannot be certain that the effect of distance from the vertical is due specifically to the environmental (i.e., gravitational) reference frame and not to the subjective (i.e., retinal) frame. This is because the two frames of reference are coincident when subjects are upright. Based on our previous findings with a head-tilt manipulation, in which subjects used either an environmental or a subjective reference frame to reference stimuli to the environmental upright (Friedman \& Hall, 1993), we think the present findings are also likely to reflect referencing the stimuli to the environmental upright. But even if they do not, the present findings are notable because they demonstrate the need to normalize unfamiliar 3-D stimuli to a vertical referent to make judgments about their shape. Whether the referent is the environment or the viewer, the normalization process seems fundamental to the shape identity judgment and, perhaps, to recognizing objects in general.

One should not lose sight of the fact that although the mental rotation task may be interesting in its own right, it is primarily so because of what it can reveal about how people determine the identity of objects under transformation. We provide further evidence that a vertical frame of reference, whether subjective or environmental, plays an important role in this process. Therefore, the present data allow us to conclude that the mental rotation function is decomposable: In a task for which the absolute position of the stimuli is, in principle, irrelevant, subjects nevertheless encode the stimuli with respect to the vertical and mentally rotate them into congruence with each other. It therefore seems likely that normalization to the vertical is one of the perceptual processes underlying object recognition in general.

\section{REFERENCES}

AutoCAD 10.0 [Computer program] (1988). Sausalito, CA: Autodesk, Inc.

Besner, D., \& Coltheart, M. (1976). Mental size scaling examined. Memory \& Cognition, 4, 525-531.

Bundesen, C., \& LARSEN, A. (1975). Visual transformation of size. Journal of Experimental Psychology: Human Perception \& Performance, 1, 214-220.

BUndesen, C., LARSEN, A., \& FarRell, J. E. (1981). Mental transformations of size and orientation. In J. Long \& A. Baddeley (Eds.) Attention and performance $I X$ (pp. 279-294). Hillsdale, NJ: Erlbaum.

COHEN, J. (1978). Partialed products are interactions; partialed powers are curve components. Psychological Bulletin, 85, 858-866.

COHEN, J., \& COHEN, P. (1975). Applied multiple regression/correlation analysis for the behavioral sciences. Hillsdale, NJ: Erlbaum.

COOPER, L. A., \& ShEPARD, R. N. (1973). Chronometric studies of the rotation of mental images. In W. G. Chase (Ed.), Visual information processing (pp. 75-176). New York: Academic Press.

Corballis, M. C. (1988). Recognition of disoriented shapes. Psychological Review, 95, 115-123.

Corballis, M. C., Nagourney, B. A., Shetzer, L. I., \& SteFanATOs, G. (1978). Mental rotation under head tilt: Factors influencing the location of the subjective reference frame. Perception $\&$ Psychophysics, 24, 263-273.

Dixon, P., \& JUST, M. A. (1978). Normalization of irrelevant dimensions in stimulus comparisons. Journal of Experimental Psychology: Human Perception \& Performance, 4, 36-46.

FINLEY, G. (1985). A high-speed plotter for vision research. Vision Research, 25, 1993-1997.

FRIEDMAN, A., \& HALL, D. L. (1993). The importance of being upright: The y-axis advantage in shape identification. Manuscript submitted for publication.

Heywood, S., \& Churcher, J. (1980). Structure of the visual array and saccadic latency: Implications for oculomotor control. Quar terly Journal of Experimental Psychology, 32, 335-341.

HUMPHREY, G. K., \& KAHN, S. C. (1992). Recognizing novel views of three-dimensional objects. Canadian Journal of Psychology, 46, 170-190.

JoLiCOEUR, P. (1985). The time to name disoriented natural objects. Memory \& Cognition, 13, 289-303.

Jolicoeur, P., Regehr, S., Smith, B. J. P., \& Smith, G. N. (1985) Mental rotation of representations of two-dimensional and three-dimensional objects. Canadian Journal of Psychology, 39, 100-129. 
Judd, C. M., \& MCClelland, G. H. (1989). Data analysis: A modelcomparison approach. New York: Harcourt Brace Jovanovich.

Just, M. A., \& CARPENTER, P. A. (1976). Eye fixations and cognitive processes. Cognitive Psychology, 8, 441-480.

Just, M. A., \& CARPENTER, P. A. (1985). Cognitive coordinate systems: Accounts of mental rotation and individual differences in spatial ability. Psychological Review, 92, 137-172.

LORCH, R. F., JR., \& MYERS, J. L. (1990). Regression analyses of repeated measures data in cognitive research. Journal of Experimental Psychology: Learning, Memory, \& Cognition, 16, 149-157.

McMullen, P. A., \& FaraH, M. J. (1991). Viewer-centered and object-centered representations in the recognition of naturalistic line drawings. Psychological Science, 2, 275-277.

McMullen, P. A., \& Jolicoeur, P. (1990). The spatial frame of reference in object naming and discrimination of left-right reflections. Memory \& Cognition, 18, 99-115.

Metzler, J., \& ShePard, R. N. (1974). Transformational studies of the internal representation of three-dimensional objects. In R. L. Solso (Ed.), Theories of cognitive psychology: The Loyola Symposium (pp. 147-201). Potomac, MD: Erlbaum.

Palmer, S., Rosch, E., \& Chase, P. (1981). Canonical perspective and the perception of objects. In J. B. Long \& A. D. Baddeley (Eds.), At tention and performance $I X$ (pp. 135-151). Hillsdale, NJ: Erlbaum.

PARSONS, L. M. (1987). Visual discrimination of abstract mirrorreflected three-dimensional objects at many orientations. Perception \& Psychophysics, 42, 49-59.

Rock, I. (1974). Orientation and form. New York: Academic Press.

Rock, I., \& DiVITA, J. (1987). A case of viewer-centered object perception. Cognitive Psychology, 19, 280-293.

SEKULER, R., \& NASH, D. (1972). Speed of size scaling in human vision. Psychonomic Science, 27, 93-94.

ShePARD, R. N., \& MetZleR, J. (1971). Mental rotation of threedimensional objects. Science, 171, 701-703.

TARR, M. J., \& PINKER, S. (1989). Mental rotation and orientation dependence in shape recognition. Cognitive Psychology, 21, 233-282.

TARR, M. J., \& PINKER, S. (1990). When does human object recognition use a viewer-centered reference frame? Psychological Science, $1,253-256$

TARR, M. J., \& PinkER, S. (1991). Orientation-dependent mechanisms in shape recognition: Further issues. Psychological Science, 2, 207-209.

Taumer, R., Lemb, M., \& Namislo, M. (1976). Characteristics of human saccadic eye movements in different directions. Albrect von Graefes Archiv für Klinische und Experimentelle Ophthalmologie, 200, 163-174.

YARBus, A. L. (1967). Eye movements and vision. New York: Plenum.

\section{NOTES}

1. We could equally consider the relation between RT and vertical distance as a function of angular disparity in the regression analyses we discuss here and elsewhere. In that case, the interpretation of the regression coefficients parallels the interpretations described in the text, except the intercept (and the change in it) and the slope (and the change in it) refer to the vertical distance functions, rather than to the angular disparity functions (e.g., the column effects in Tables 1-4 rather than the row effects). The two ways of considering the data are statistically equivalent. That is, the parameter estimates for the regression coefficients do not change, and their interpretation is symmetric. Since all of the previous literature on the mental rotation task is framed in terms of the relation between RT and the angular disparity between the objects, we chose to examine this relation as a function of vertical distance, rather than the other way around

2. It is not a straightforward matter to add the interaction term to the regression equation in the present case, because, although the two individual predictor variables are uncorrelated (due to the orthogonal nature of the design), they each are correlated with the values of their interaction (i.e., the correlation between the values of angular disparity and disparity $\times$ distance is .500 ; the correlation between vertical dis- tance and the interaction values is .791). This wreaks havoc with the tolerance values for the regression coefficients. The problem can be alleviated altogether, with no change in power, by transforming the predictor variables to mean deviation scores and/or by conducting hierarchical analysis, but then the interpretations of $\beta_{0}, \beta_{1}$, and $\beta_{2}$ change in the interactive prediction equation (J. Cohen, 1978; J. Cohen \& P. Cohen, 1975; Judd \& McClelland, 1989). In particular, $\beta_{0}$ becomes the predicted value of the intercept at the mean values of angular disparity and vertical distance (because, for the transformed scores, this is when they equal zero), $\beta_{1}$ becomes the slope of the angular disparity function (i.e., the slope for the main effect of angular disparity), and $\beta_{2}$ becomes the slope of the vertical distance function (i.e., the slope for the main effect of vertical distance). Thus, these values are the same as they are in the additive model. Fortunately, the interpretation of $\beta_{3}$ (the interaction coefficient) does not change with linear transformations of the predictor variables (J. Cohen \& P. Cohen, 1975; Judd \& McClelland, 1989); it still reflects the change in the slope of the angular disparity function as a function of vertical distance. Consequently, in this and subsequent experiments, we transformed the disparity and distance values to deviation scores, and we used these values to compute regression coefficients for individual subjects, to determine whether the three regression coefficients differed from zero (see Lorch \& Myers, 1990). We conducted hierarchical regression analyses, with the two main-effect factors entered first, to determine the unique contributions of the variables and their interaction in reducing the variance in the RTs.

\section{APPENDIX \\ Error Data for All Same Trial Conditions in Experiments 1-3}

\begin{tabular}{|c|c|c|c|c|c|}
\hline \multirow{2}{*}{$\begin{array}{c}\text { Distance } \\
\text { From Vertical }\end{array}$} & \multicolumn{4}{|c|}{ Angular Disparity Between Objects } & \multirow[b]{2}{*}{$M$} \\
\hline & $15^{\circ}$ & $30^{\circ}$ & $45^{\circ}$ & $60^{\circ}$ & \\
\hline \multicolumn{6}{|c|}{ Experiment 1} \\
\hline $0^{\circ}$ & 4.2 & 4.2 & 4.2 & 6.3 & 4.7 \\
\hline $15^{\circ}$ & 0.0 & 0.0 & 10.4 & 8.3 & 4.7 \\
\hline $30^{\circ}$ & 2.1 & 2.1 & 2.1 & 10.4 & 4.2 \\
\hline $45^{\circ}$ & 2.1 & 2.1 & 2.1 & 18.8 & 6.3 \\
\hline $60^{\circ}$ & 0.0 & 2.1 & 4.2 & 12.5 & 4.7 \\
\hline$M$ & 1.7 & 2.1 & 4.6 & 11.3 & \\
\hline \multicolumn{6}{|c|}{ Experiment 2} \\
\hline $0^{\circ}$ & 0.0 & 2.1 & 4.2 & 12.5 & 4.7 \\
\hline $15^{\circ}$ & 4.2 & 4.2 & 6.3 & 6.3 & 5.2 \\
\hline $30^{\circ}$ & 0.0 & 2.1 & 8.3 & 10.4 & 5.2 \\
\hline $45^{\circ}$ & 2.1 & 4.2 & 6.3 & 14.6 & 6.8 \\
\hline $60^{\circ}$ & 0.0 & 4.2 & 2.1 & 8.3 & 3.6 \\
\hline$M$ & 1.3 & 3.3 & 5.4 & 10.4 & \\
\hline \multicolumn{6}{|c|}{ Experiment 3: Picture Plane } \\
\hline $0^{\circ}$ & 0.0 & 4.2 & 4.2 & 2.1 & 2.6 \\
\hline $15^{\circ}$ & 0.0 & 2.1 & 6.3 & 6.3 & 3.6 \\
\hline $30^{\circ}$ & 0.0 & 0.0 & 6.3 & 6.3 & 3.1 \\
\hline $45^{\circ}$ & 0.0 & 2.1 & 4.2 & 6.3 & 3.1 \\
\hline $60^{\circ}$ & 0.0 & 2.1 & 4.2 & 8.3 & 3.6 \\
\hline$M$ & 0.0 & 2.1 & 5.0 & 5.8 & \\
\hline \multicolumn{6}{|c|}{ Experiment 3: Depth } \\
\hline $0^{\circ}$ & 2.1 & 0.0 & 10.2 & 6.9 & 4.9 \\
\hline $15^{\circ}$ & 2.1 & 0.0 & 8.3 & 2.1 & 3.1 \\
\hline $30^{\circ}$ & 2.1 & 0.0 & 2.1 & 8.3 & 3.1 \\
\hline $45^{\circ}$ & 4.2 & 4.2 & 4.2 & 4.2 & 4.2 \\
\hline $60^{\circ}$ & 4.2 & 6.3 & 6.3 & 12.5 & 7.3 \\
\hline$M$ & 2.9 & 2.1 & 6.3 & 6.8 & \\
\hline
\end{tabular}

(Manuscript received August 27, 1993; revision accepted for publication October 15, 1993.) 